\title{
OPTIMAL HEDGING UNDER DEPARTURES FROM THE COST-OF-CARRY VALUATION: EVIDENCE FROM THE SPANISH STOCK INDEX FUTURES MARKET.
}

November 2001

\begin{abstract}
We provide an analytical discussion of the optimal hedge ratio under discrepancies between the futures market price and its theoretical valuation according to the cost-of-carry model. Assuming a geometric Brownian motion for spot prices, we model mispricing as a specific noise component in the dynamics of futures market prices. Empirical evidence on the model is provided for the Spanish stock index futures. Ex-ante simulations with actual data reveal that hedge ratios that take into account the estimated, time-varying, correlation between the common and specific disturbances, lead to using a lower number of futures contracts than under a systematic unit ratio, without generally losing hedging effectiveness, while reducing transaction costs and capital requirements. Besides, the reduction in the number of contracts can be substantial over some periods. Finally, a meanvariance expected utility function suggests that the economic benefits from an optimal hedge are substantial.
\end{abstract}

Key words: Optimal hedging; Futures contract; Stock Index; GARCH models; Mispricing.

JEL classification: C51, G11, G13. 


\section{Introduction}

Since its launching in January 1992, the Ibex 35 futures contract quickly became the most actively traded derivative contract in Meff Renta Variable, the Spanish equity derivatives exchange. In fact, the futures market on the Spanish Ibex 35 stock index is also one of the most active futures stock index markets in the world. Acceptance of a market for a stock index futures contract is related to the hedging ability of this derivative instrument. Operating with futures, it is not only possible to guarantee a certain profit, but to also bound the losses obtained over a given time period. Hedging spot positions in the Spanish stock market became especially relevant in recent years, because the systematic decrease in interest rates as a consequence of the fiscal and monetary policies aimed to achieve the European Union, caused a dramatic reallocation of private savings from riskless assets to stock exchange positions.

The relevant issue in a hedging operation is to determine the hedge ratio, which provides the number of futures contracts that must be sold to counteract the opposite evolution in spot prices, so that, the potential losses in one market can be offset by the gains obtained in the other. A biased estimation of the hedge ratio implies that the losses in one market will be higher or lower than the profits in the other one. This is troublesome for a hedging strategy, whose aim is to transform a position in the spot market into a riskless portfolio.

According to the cost-of-carry valuation (the standard forward pricing model), which assumes perfect markets and non stochastic interest rates and dividend yields, the theoretical price at time $t\left(F_{t, T}^{*}\right)$ of an index futures contract maturing at time $T$ equals the opportunity cost of keeping a basket replicating the spot index between $t$ and $T$ :

$$
F_{t, T}^{*}=S_{t} e^{(r-d)(T-t)},
$$

where $S_{t}$ is the index value and $(r-d)$ is the net cost of carry associated to the underlying stocks in the index, i.e., the riskless rate of return minus the dividend yield of the stocks in the index. Alternatively, equation (1) can be written:

$$
r_{s, t}=r_{f^{*}, t}+(r-d),
$$

where $r_{s, t}=\ln \left(\frac{S_{t}}{S_{t-1}}\right)$ and $r_{f^{*}, t}=\ln \left(\frac{F_{t, T}^{*}}{F_{t-1, T}^{*}}\right)$, the spot and theoretical futures 
returns, respectively. Under the previous assumptions, the relationship in (2) implies that: $a$ ) the variance of returns in the spot market equals the variance of returns in the futures market, $b$ ) the contemporaneous rates of return of the underlying stock index and the futures contract are perfectly and positively correlated, and $c$ ) the non-contemporaneous rates of return are uncorrelated and no lead-lag relationships between returns should appear. However, in the presence of market imperfections such as transactions costs, asymmetric information, capital requirements and short-selling restrictions, there could be discrepancies between the traded futures price and its theoretical valuation according to the cost-of-carry model (see Mackinlay and Ramaswamy (1988), Lim (1992), Miller et al. (1994), Yadav and Pope (1990, 1994), and Bühler and Kempf (1995), among others).

Market imperfections may also produce a lead-lag relationship between spot and futures market returns, as well as between their volatilities. Then, it may be possible to anticipate price movements and risk fluctuations in one market from past information in the other market, a relevant question when using the futures contract as a hedging instrument for risky stock portfolios. In fact, there is a wealth of studies showing empirical evidence for the main international stock index futures markets supporting the existence of such lead-lag relationships (see, for example, Stoll and Whaley (1990), Wahab and Lasghari (1993), Pizzi et al. (1998), Iihara et al. (1996), Koutmos and Tucker (1996), and Racine and Ackert (1998), among others).

We start by providing empirical evidence in favor of significant mispricing in the Spanish stock index futures market. Assuming that the evolution of the stock index and the futures market returns are driven by heteroscedastic, geometric Brownian motion processes, we include a market-specific noise in the dynamics of theoretical futures returns. The motivation for such a noise is that, by itself, it produces a spread between theoretical and market futures prices, although such a hypothesis would only make sense when volatility in the spot and futures markets could not be summarized by a single factor. We use Engle and Kozicki (1993) approach to test for a single common $A R C H$ factor between the two markets, conclusively rejecting such hypothesis. Hence, the two markets do not share an identical source of volatility, against the cost-of-carry model.

We also provide empirical evidence for this model using data from 20/12/93 to 20/12/96 from the Spanish stock index futures market. A bivariate error correction model with $G A R C H$ perturbations is used to estimate the conditional second moments of market returns. Our model has the follow- 
ing characteristics: $a$ ) it incorporates the long-run equilibrium relationship between spot and futures prices, $b$ ) it takes into account the cross-market interactions between returns and volatilities, $c$ ) it does not impose a constant conditional correlation coefficient in the matrix of second moments for market returns, a significant difference with most previous analysis (Park and Switzer (1995), Iihara et al. (1996), Koutmos and Tucker (1996), Racine and Ackert (1998), and Lien and Tse (1999), among others), and $d$ ) it captures the presence of an intraday $U$-shaped seasonal pattern for both spot and futures market volatility. Our model specification and technique estimation allow us to capture stochastically this intraday seasonal pattern for market volatilities rather than through deterministic variables, as it is standard in the literature. We estimate the model with hourly returns, using the nearest to maturity contract, to then recover estimates for the parameters in the theoretical model. Our estimates imply a less than perfect correlation between spot and futures returns, leading to an optimal hedge ratio below one to hedge the spot index portfolio, without losing any hedging effectiveness in ex-ante simulations of hedging strategies using actual data.

The rest of the paper is organized as follows. The optimal hedge ratio under departures from cost of carry valuation is analytically derived in Section 2, and its main properties are discussed. In Section 3 we describe the data used in our analysis. We start Section 4 with some preliminary empirical evidence on regularities in returns and volatilities in Spanish spot and futures stock markets. We then present the econometric approach followed to estimate dynamic relationships across markets in conditional first and second order moments for returns, discussing the main results. In Section 5 we recover estimates for the theoretical parameters of the model. In Section 6 we make ex-ante simulations to investigate if taking into account departures from the theoretical cost-of-carry valuation enhances the hedging effectiveness of the futures contract. Finally, Section 7 summarizes and presents concluding remarks.

\section{The optimal hedge ratio}

Let us assume that spot prices evolve according to a geometric Brownian motion:

$$
d S_{t}=\mu_{s, t} S_{t} d t+\sigma_{s, t} S_{t} d z_{1, t}
$$


where $S_{t}$ is the index value, $\mu_{s, t}$ and $\sigma_{s, t}$ are the conditional mean and standard deviation of spot returns, and $d z_{1, t}=\varepsilon_{1 t} \sqrt{d t}$, with $\varepsilon_{1 t}$ i.i.d. $\sim N(0,1)$, a Wiener process. Taking into account the no arbitrage relationship between spot and futures prices (1), the process for the evolution of the theoretical price of a futures contract can be obtained applying Ito's lemma:

$$
d F_{t, T}^{*}=\mu_{f, t} F_{t, T}^{*} d t+\sigma_{s, t} F_{t, T}^{*} d z_{1, t},
$$

where $\mu_{f, t}=\mu_{s, t}-(r-d)$. In perfect markets, the no arbitrage equilibrium relationship is expected to hold, and the volatility of spot and futures returns should be the same. However, there is a wealth of studies showing systematic discrepancies between the traded futures price and its theoretical price according to the cost-of-carry valuation. In that situation, (4) would not be the correct representation of the dynamic evolution of the traded futures price. We model such discrepancy by introducing a second noise specific to the derivative market:

$$
d F_{t, T}=\mu_{f, t} F_{t, T} d t+\sigma_{s, t} F_{t, T} d z_{1, t}+\sigma_{N, t} F_{t, T} d z_{2, t}
$$

where $F_{t, T}$ is the traded futures price and $d z_{2, t}=\varepsilon_{2 t} \sqrt{d t}$, with $\varepsilon_{2 t}$ i.i.d. $\sim N(0,1)$. We do not impose any restriction on the conditional correlation between the common noise $\left(\varepsilon_{1 t}\right)$ and the specific disturbance for the futures market $\left(\varepsilon_{2 t}\right)$, which we denote by $\rho_{12, t}$. Under (5), market returns will not exhibit a perfect and positive correlation. From (3) and (5), the correlation coefficient between returns, $\rho_{s f, t}$, can be written:

$\rho_{s f, t}=\frac{\operatorname{Cov}_{t}\left(\frac{d S_{t}}{S_{t} d t}, \frac{d F_{t, T}}{F_{t, T} d t}\right)}{\sqrt{\left[\operatorname{Var}_{t}\left(\frac{d S_{t}}{S_{t} d t}\right)\right]\left[\operatorname{Var}_{t}\left(\frac{d F_{t, T}}{F_{t, T} d t}\right)\right]}}=\frac{\sigma_{s, t}^{2}+\rho_{12, t} \sigma_{s, t} \sigma_{N, t}}{\sqrt{\sigma_{s, t}^{2}\left(\sigma_{s, t}^{2}+\sigma_{N, t}^{2}+2 \rho_{12, t} \sigma_{s, t} \sigma_{N, t}\right)}}$

Only when $\sigma_{N, t}=0$, that is, when the two markets share the same noise, a perfect and positive conditional correlation between market returns will be observed.

It is assumed that the hedger holds a long spot position $b_{t}$ and intends to short futures to minimize the variance of the return from the hedged position over a given investment horizon. The hedge ratio is the number of monetary units allocated to the short futures position per monetary unit invested in 
the cash market. Denoting by $h_{t}$ the short futures position, the investor's hedging decision in a two period framework is:

$$
\begin{aligned}
& \operatorname{MinVar}_{t}\left(b_{t} \frac{d S_{t}}{S_{t} d t}-h_{t} \frac{d F_{t, T}}{F_{t, T} d t}\right) \\
& \left\{h_{t}\right\} \\
& \text { s.t. } \quad \begin{array}{l}
d S_{t}=\mu_{s, t} S_{t} d t+\sigma_{s, t} S_{t} d z_{1, t} \\
\quad d F_{t, T}=\mu_{f, t} F_{t, T} d t+\sigma_{s, t} F_{t, T} d z_{1, t}+\sigma_{N, t} F_{t, T} d z_{2, t}
\end{array}
\end{aligned}
$$

which amounts to:

$$
\begin{aligned}
& \operatorname{Min} b_{t}^{2} \sigma_{s, t}^{2}\left[1+\left(\frac{h_{t}}{b_{t}}\right)^{2}\left(1+\delta_{t}^{2}+2 \rho_{12, t} \delta_{t}\right)-2\left(\frac{h_{t}}{b_{t}}\right)\left(1+\rho_{12, t} \delta_{t}\right)\right] \\
& \left\{h_{t}\right\}
\end{aligned}
$$

where $\delta_{t}=\frac{\sigma_{N, t}}{\sigma_{s, t}}$ denotes the relative size of the specific noise in terms of the common noise.

As shown in appendix 1, this problem leads to the optimal hedge ratio:

$$
\frac{h_{t}^{*}}{b_{t}}=\frac{\sigma_{s, t}^{2}+\rho_{12, t} \sigma_{s, t} \sigma_{N, t}}{\sigma_{s, t}^{2}+\sigma_{N, t}^{2}+2 \rho_{12, t} \sigma_{s, t} \sigma_{N, t}}=\frac{1+\rho_{12, t} \delta_{t}}{1+\delta_{t}^{2}+2 \rho_{12, t} \delta_{t}},
$$

This analytical description of the optimal ratio is undetermined only when $\rho_{12, t}=-1$ and $\delta_{t}=1$. In this particular case, $1+\delta_{t}^{2}+2 \rho_{12, t} \delta_{t}=1+$ $\rho_{12, t} \delta_{t}=0$, and the objective function is equal to the variance of the unhedged position, $b_{t}^{2} \sigma_{s, t}^{2}$, regardless of the hedge ratio. The futures price then becomes non-stochastic and it does not provide any hedging capability. When this situation arises, the optimal hedge ratio will be zero if there is any hedging cost.

In the general case, the minimized conditional variance of the hedged position is:

$b_{t}^{2} \sigma_{s, t}^{2}\left(1+\frac{1+\rho_{12, t} \delta_{t}}{1+\delta_{t}^{2}+2 \rho_{12, t} \delta_{t}}-2 \frac{1+\rho_{12, t} \delta_{t}}{1+\delta_{t}^{2}+2 \rho_{12, t} \delta_{t}}\right)=b_{t}^{2} \sigma_{s, t}^{2} \delta_{t}^{2} \frac{1-\rho_{12, t}^{2}}{1+\delta_{t}^{2}+2 \rho_{12, t} \delta_{t}}$

with $\delta_{t}^{2} \frac{1-\rho_{12, t}^{2}}{1+\delta_{t}^{2}+2 \rho_{12, t} \delta_{t}}$ being the variance reduction factor, i.e., the ratio between the conditional variances of the hedged and unhedged position. 
Proposition 1 The optimal hedge ratio is just a function of: a) the relative standard deviation of the specific and common disturbances, and b) the conditional correlation between both noises.

Proof: See equation (8).

Proposition 2 If $\delta_{t}=\frac{\sigma_{N, t}}{\sigma_{s, t}} \rightarrow 0$ the optimal hedge ratio converges to one and the minimized variance of the global position return approaches zero. Both limits hold regardless of the correlation between the specific and common innovations.

Proof: From (10) and(11), $\frac{h_{t}^{*}}{b_{t}} \rightarrow 1$ and the variance reduction factor converges to zero when $\delta_{t}=\frac{\sigma_{N, t}}{\sigma_{s, t}} \rightarrow 0$, for any value of $\rho$.

As the relative size of the standard deviation of the specific noise approaches zero, spot and futures market innovations become increasingly similar. Consequently, both markets tend to share a common noise and the optimal hedge ratio converges to one, the optimal value when there are no discrepancies between the traded price of a futures contract and its valuation according to the cost-of-carry model. As expected, under no departures from the cost of carry valuation full hedging effectiveness is achieved and the risky spot position can be safely converted into a riskless portfolio.

Proposition 3 If $\delta_{t}=\frac{\sigma_{N, t}}{\sigma_{s, t}} \rightarrow \infty$ the optimal hedge ratio converges to zero, regardless of the correlation between the specific and common innovations.

Proof: From (10), $\frac{h_{t}^{*}}{b_{t}} \rightarrow 0$ when $\delta_{t}=\frac{\sigma_{N, t}}{\sigma_{s, t}} \rightarrow \infty$.

If the specific futures market noise becomes very large, relative to the common market noise, spot market fluctuations are relatively negligible. In this case, a small number of futures contracts is needed to cover the spot position. The minimized variance of the global position return approaches $b_{t}^{2} \sigma_{t}^{2}\left(1-\rho_{12, t}^{2}\right)$, and the variance reduction factor depends on the correlation between common and specific innovations. 
Proposition 4 Under either positive or zero correlation between the specific and common disturbances, the optimal hedge ratio is positive, less than 1, and decreasing in $\delta_{t}$.

Proof: When $\rho_{12, t} \in[0,1],(10)$ is always positive. The inequality $1+$ $\rho_{12, t} \delta_{t}<1+\delta_{t}^{2}+2 \rho_{12, t} \delta_{t}$ holds, so the hedge ratio is below one. Finally, the derivative of $\frac{h_{t}^{*}}{b_{t}}$ in (10) with respect to $\delta_{t}$ is negative for $\rho_{12, t}>0$.

If the specific and common noises are positively correlated, fluctuations in the futures market tend to follow those of the spot market. Consequently, to cover a spot position we need to sell futures in a given proportion of the resources allocated to the long spot position. As $\delta_{t}$ increases, fluctuations in the futures market amplify those of the spot index, and an increasingly smaller number of futures needs to be sold, so the optimal hedge ratio decreases to zero. A similar argument also applies under zero correlation.

Proposition 5 The optimal hedge ratio is monotonically increasing (decreasing) in the correlation between specific and common innovations if $\delta_{t}<$ $1(>1)$.

Proof: The derivative of $\frac{h_{t}^{*}}{b_{t}}$ in (10) with respect to $\rho$ is positive if $\delta_{t}<1$, and positive if $\delta_{t}>1$.

Proposition 6 i) If the common and specific innovations are perfect and positively correlated, the optimal hedge ratio is $\frac{h_{t}^{*}}{b_{t}}=\frac{1}{1+\delta_{t}}$ and we achieve full risk hedging, ii) if the common and specific noises are perfect and negatively correlated, the optimal hedge ratio is $\frac{h_{t}^{*}}{b_{t}}=\frac{1}{1-\delta_{t}}$ and we again achieve full risk hedging.

Proof: Both results are easily obtained from (10) and (11).

For non-zero values of $\delta_{t}$, and a positive correlation between specific and common noises, full hedging is only achieved under $\rho_{12, t}=1$ or $\rho_{12, t}=-1$. From (6), $\rho_{12, t}=1$ amounts to $\rho_{s f, t}=1$, perfect correlation between returns in both markets, as assumed by the cost-of-carry valuation model. On the other hand, $\rho_{12, t}=-1$ amounts to either $\rho_{s f, t}=1$ (if $\delta_{t}<1$ ), or $\rho_{s f, t}=-1$ 
(if $\delta_{t}>1$ ), and in both cases we can get a perfect hedge. When correlation is less than perfect, the minimized variance of the hedged position is given by (11), and it is strictly positive.

Proposition 7 The optimal hedge ratio is negative if and only if $\delta_{t}>1$ and $-\frac{1+\delta^{2}}{2 \delta}<\rho_{12, t}<-1 / \delta_{t}$.

Proof: For a given $\rho_{12, t}$, the optimal hedge ratio can be written: $\frac{h_{t}^{*}}{b_{t}}=$ $\frac{1+\rho_{12, t} \delta_{t}}{1+\delta_{t}^{2}+2 \rho_{12, t} \delta_{t}}=\frac{\varphi_{1}\left(\rho_{12, t}\right)}{\varphi_{2\left(\rho_{12, t}\right)}}$, with $\varphi_{1}\left(\rho_{12, t}\right)<0$ iff $\rho_{12, t}<-1 / \delta_{t}$, and $\varphi_{2}\left(\rho_{12, t}\right)<0$ iff $\rho_{12, t}<-\frac{1+\delta^{2}}{2 \delta}$. When $\delta_{t}<1$, we have: $-1 / \delta_{t}<-\frac{1+\delta^{2}}{2 \delta}<-1<\rho_{12, t}$, and the optimal hedge ratio is positive. When $\delta_{t}>1$, we have: $-\frac{1+\delta^{2}}{2 \delta}<-1 / \delta_{t}$. In that case, if $\rho_{12, t}<-\frac{1+\delta^{2}}{2 \delta}$ we have $\varphi_{1}\left(\rho_{12, t}\right)<0, \varphi_{2}\left(\rho_{12, t}\right)<0$, and $\frac{h_{t}^{*}}{b_{t}}>0$. If $\rho_{12, t}>-1 / \delta_{t}, \varphi_{1}\left(\rho_{12, t}\right)>0, \varphi_{2}\left(\rho_{12, t}\right)>0$, and again $\frac{h_{t}^{*}}{b_{t}}>0$. Finally, if $\delta_{t}>1$ and $-1<\rho_{12, t}<-1 / \delta_{t}$, we have $\varphi_{1}\left(\rho_{12, t}\right)<0, \varphi_{2}\left(\rho_{12, t}\right)>0$, and $\frac{h_{t}^{*}}{b_{t}}<0$.

For the range of correlation values between the common and specific noises mentioned in the proposition, we should take the same position in both, spot and futures markets. This makes sense when the specific noise is relatively large $\left(\delta_{t}>1\right)$ and displays a large enough negative correlation with the common noise since then the innovation in the futures market tends to fluctuate in the opposite direction to the spot market innovation. This is a situation unlikely to arise in practice.

Figures 1 and 2 (appendix 2) show the optimal hedge ratio as a function of either the correlation between specific and common noises, $\rho_{12, t}$, or their standard deviation ratio, $\delta_{t}$, for given values of the other parameter. Figure 1 shows that, under positive correlation between the two noises, the optimal hedge ratio decreases as the standard deviation ratio increases, since then the futures market provides better diversifying opportunities. Figure 2 shows that for most correlations, the optimal hedge ratio is quite robust to moderate changes in the market noise ratio ${ }^{1}, \delta_{t}$.

\footnotetext{
${ }^{1}$ For a large negative correlation, the hedge ratio may be above one if $\delta_{t}$ is low. There is then also a significant range for $\delta_{t}$ in which the optimal decision to minimize the return variance of the global position is to buy, rather than sell, futures. However, such a large, negative correlation should be considered unlikely.
} 
Therefore, as expected, incorporating departures from the cost of carry valuation of the futures contract enriches the hedging analysis. The model suggests that, if the futures markets has a specific noise and, consequently, the spot and futures markets do not share an identical disturbance, the optimal "short futures position" requires a less than proportional allocation relative to the long spot position provided that the specific and common noises are uncorrelated or positively correlated. On the other hand, under a negative correlation between the two noises, the optimal hedge ratio per unit long spot position might be above or below one, and it might lead in extreme cases to also taking a long position in the futures market.

\section{The data on Spanish markets}

We now proceed to analyze the empirical evidence on the model proposed in the previous section. Data on the futures market on the Ibex 35 Spanish stock market index was provided by MEFF RV (Mercado Español de Futuros, Renta Variable) for the period December 15, 1993-December 15, 1996. This period is interesting for three reasons: $a$ ) by December 1993, the initial years of exponential growth in the Spanish stock index futures market had already ended, becoming a highly liquid market; b) negotiated volume stabilized around three million contracts per year, and c) it covers three different episodes for the Spanish stock market: during 1994, market capitalization registered an annual loss of almost 7\%; 1995 was characterized by high price fluctuations and a moderate return, while 1996 shown a systematic growth in the Ibex 35, with an annual return close to $40 \%$. Hence, the period analyzed can be considered as a representative sample of all possible market scenarios.

We have matched two data sets: one concerning the price and transaction time for each trade in the futures contract on the Ibex 35 index, and another with minute by minute Ibex 35 index data. An important source of bias when estimating conditional second order moments of spot and futures market returns can be the use of non-synchronous data. We eliminate this possibility by matching each futures price with the cash index value observed at the same minute. This way, we have two price series matched to the minute. Since the opening cash index is reflecting closing spot prices from the previous day, we remove the first hour trading interval for the spot market ${ }^{2}$, and select hourly

\footnotetext{
${ }^{2}$ The futures market opens at 10:45 ${ }^{\mathrm{AM}}$. With data between December 1993 and November 1994, Fernández and Yzaguirre (1996) show that, most often, it is just after 11:00 ${ }^{\mathrm{AM}}$
} 
market prices between 11:00 and 17:00 hours. We also exclude overnight returns because they are measured over a longer time period, to end up with six observations for each trading day. From these hourly prices we generate the percent return series for each market by taking the first difference of the natural logarithm of prices, multiplied by 100 . Since the nearest to maturity contract is systematically the most actively traded, only data for the nearby futures contract is used. Switching is made to the next contract on the third Friday of each month, when a futures contract matures. Even though in some markets switching to the next contract is made before maturity to ensure sufficient volume of trade, in the Spanish market there is enough liquidity to allow for exhausting the contract period. Therefore, we handle 36 futures contracts along the sample, with 743 trading days ${ }^{3}$. Overall, we have 4,458 return observations for each market.

For each registered time, we calculate the theoretical price $F_{t, T}^{*}$ for a futures contract maturing at time $T$ according to the discrete analogue of 1 ,

$$
F_{t, T}^{*}=S_{t}\left(1+r_{t, T}\right)-\sum_{i} \sum_{j \gg t}^{T} \frac{d_{i j}}{P_{i j}} \omega_{i, j} S_{j}\left(1+r_{j, T}\right),
$$

where: $S_{j}$ is the cash index at time $j, r_{j, T}$ is the risk free rate of return between $t$ and $T, d_{i, j}$ is the gross dividend paid in period $j$ on the $i-t h$ component of the Ibex 35, $P_{i j}$ is the stock market price of that component at time $j$, and $\omega_{i j}$ is its weight in Ibex 35. We have used as risk-free return the interest rate on repo operations in the secondary market for Spanish Treasury bills. To actually compute theoretical prices, we proceed backwards starting at maturity of each contract, using actual dividend and interest rate data. Hence, a cost-of-carry varying according to market conditions is taken into account ${ }^{4}$. Then, we compute mispricing at time $t$ as the absolute spread between actual futures market prices $F_{t, T}$, and our theoretical cost-of-carry valuation, $M_{t}=\left|F_{t, T}-F_{t, T}^{*}\right|$.

Deviations from the theoretical futures price may be positively related to the contract maturity, due to a greater risk of unanticipated dividend changes, unanticipated earnings or financing costs of marking to market, or

\footnotetext{
that all the 35 assets in the Ibex 35 have been negotiated at least once.

${ }^{3}$ We could not include data from: 02/14/95, 12/27/96, 05/27/96 and 07/29/96 because they were incomplete in the Meff Renta Variable tapes.

${ }^{4}$ Average daily mispricing was 11.4, 8.4 and 5.8 basis points over 1994, 1995 and 1996, respectively. Annual cost-of-carry was $4.9 \%, 6.4 \%$ and $5.4 \%$ for each of three years.
} 
difficulties to track the index in the spot market directly, as suggested by MacKinlay and Ramaswamy (1988), Bhatt and Caciki (1990), and Brenner and Kroner (1995), among others. A regression of average mispricing on time to maturity yielded a low $R$-squared of 0.10 , but a significant coefficient of 0.319 , with standard deviation of 0.037 . This is evidence that increased uncertainty leads in fact to larger deviations from the theoretical price for longer maturities.

A different issue concerns the possibility that treating the risk-free interest rate and the dividend yield as being constant might seriously bias the evidence of mispricing. Even though we have used the actual, time varying net cost-of-carry, we checked that spurious evidence of mispricing is not produced by a residual effect from time variation in the cost-of-carry components. Regressions from daily mispricing on interest rates or the dividend yield produced in each case a non significant slope and a near to zero $R$ squared. When added to time-to-maturity as explanatory variables in the mispricing regression, these variables did not contribute with any significant explanatory power. This analysis suggests that we can safely consider that indeed, the use of actual interest rate and dividend data avoids the bias that could arise by imposing a constant cost-of-carry.

\section{Estimating a volatility transmission model}

\subsection{Some statistical characteristics}

Tables 1 to 3 present descriptive statistics for intraday hourly returns, as well as for squared returns, in both markets. Table 1 shows the mean, standard deviation, skewness, kurtosis and autocorrelation functions for spot and futures market returns. As expected, the mean return is very small in both markets, the null hypothesis of a zero mean not being rejected in either case. There is slight negative skewness and heavy tails in both return series, compared with the Normal distribution. Departures from Normality are however, more important in the spot market, where the central cluster is sharper. Both return series exhibit positive first order autocorrelation, suggesting that the observed return anticipates a return of the same sign next hour. However, that autocorrelation coefficient is significant at the $5 \%$ level just for the spot market. This is consistent with the argument that infrequent trading of stocks in the index portfolio causes a larger inertia in the stock index (see, 
for example, Miller et al. (1994)).

Autocorrelation coefficients for squared intraday returns are displayed in Table 2. Estimated coefficients slowly decrease to zero, revealing non-linear dependence in the return series in both markets. Therefore, to analyze the intraday causal relationship between spot and futures markets, the methodology representing the dynamics of market returns must take into account higher order dependence, possibly as a result of changing volatility over time. Interestingly enough, estimated autocorrelation coefficients for lags multiple of six are systematically positive and significant, being much higher than the rest. This structure may be motivated by an intraday seasonal pattern in volatility in both markets, since we have 6 data points each market day. This is consistent with Chan et al. (1991) and Daigler (1997), among others, which find evidence of a $U$-shape pattern of volatility along the day. Lafuente (1999) has characterized the same regularity for the spot and futures markets on the Spanish Ibex 35 index.

Table 3 shows the cross correlation function between intraday cash and futures returns. The estimated contemporaneous correlation of 0.67 is high, but it is not close to one, the value implied by the cost-of-carry model. The first lagged return in each market seems to contain some forecasting power regarding the return in the other market, although predictability seems to be more important from the futures to the spot market than in the other direction. Both estimated coefficients are positive, showing that, in the shortrun, price movements occur in the same direction in both markets.

Since there is not much dynamic structure in returns, squared market returns are a good proxy for conditional variances. Table 3 presents their cross-correlation function, suggesting highly persistent cross-market volatility interactions. These preliminary results indicate that a lead-lag relationship exists not only between market returns, but also between their volatilities. We incorporate these findings in the modeling strategy that follows.

Besides, a contemporaneous correlation well below one suggests that more than a single common $A R C H$ factor may be needed to explain fluctuations in volatility over time in both markets. To formally test this hypothesis we provide in Table 4 results from the Engle and Kozicki (1993) test for an $A R C H$ common feature between the two return series, showing a clear rejection of this hypothesis, in agreement with our theoretical model in Section 2. 


\subsection{The model for returns and volatilities in spot and futures markets}

To estimate the conditional variance-covariance matrix of spot and futures returns in a model that correctly represents the dynamics of intraday returns in both markets, as well as their interactions, a model should be specified capturing $a$ ) the cross-market dependence between returns, $b$ ) the crossinteractions between volatilities, and $c$ ) the presence of an intraday seasonal pattern in spot and futures market volatilities.

We use an error correction ${ }^{5}$ model with $G A R C H$ innovations. Let $r_{s, t}$ and $r_{f, t}$ be the market returns, that is, $r_{s, t}=s_{t}-s_{t-1}$, and $r_{f, t}=f_{t}-f_{t-1}$, where $s_{t}$ and $f_{t}$ denote the logarithm of spot index and trading futures prices respectively. The dynamics governing intraday market returns are described by:

$\left(\begin{array}{l}r_{s, t} \\ r_{f, t}\end{array}\right)=\left(\begin{array}{ll}\alpha_{11} & \alpha_{12} \\ \alpha_{21} & \alpha_{22}\end{array}\right)\left(\begin{array}{c}r_{s, t-1} \\ r_{f, t-1}\end{array}\right)+\left(\begin{array}{c}\beta_{s} \\ \beta_{f}\end{array}\right)\left(s_{t-1}-\left(\gamma_{1}+\gamma_{2} f_{t-1}\right)\right)+\left(\begin{array}{c}\varepsilon_{s, t} \\ \varepsilon_{f, t}\end{array}\right)$

with $\varepsilon_{t}$, the vector of innovations having a conditional distribution: $\varepsilon_{t}=$ $\left(\begin{array}{ll}\varepsilon_{s, t} & \varepsilon_{f, t}\end{array}\right)^{\prime}{ }_{t-1}^{\sim} N\left(0, \Sigma_{t}\right)$, where ${ }_{t-1}$ is the information set available at time $t-1$ and $\Sigma_{t}$ is the conditional covariance matrix of returns. We include as explanatory variable $s_{t-1}-\left(\gamma_{1}+\gamma_{2} f_{t-1}\right)$, an error correction term incorporating the short-run adjusting mechanism to deviations from the long- run equilibrium relationship.

$>$ From standard notation, the second order moment dynamics corresponding to a $G A R C H(p, q)$ model can be represented:

$$
\operatorname{vech} \Sigma_{t}=\operatorname{vech} \bar{\Sigma}+\Theta_{q}(B) \operatorname{vech}\left(\varepsilon_{t} \varepsilon_{t}^{\prime}\right)+\Psi_{p}(B) \operatorname{vech} \Sigma_{t}
$$

with $\Phi(0)=\Theta(0)=0, B$ being the backshift operator, $\varepsilon_{t}$ the innovation vector, vech $\Sigma_{t}=\left(\begin{array}{llll}\sigma_{s, t}^{2} & \sigma_{s f, t} & \sigma_{f, t}^{2}\end{array}\right)^{\prime}$, and vech $\left(\varepsilon_{t} \varepsilon_{t}^{\prime}\right)=\left(\begin{array}{lll}\varepsilon_{s, t}^{2} & \varepsilon_{s, t} \varepsilon_{f, t} & \varepsilon_{f, t}^{2}\end{array}\right)^{\prime}$.

\footnotetext{
${ }^{5}$ We tested the cointegration hypothesis through three tests proposed by Engle and Granger (1987). The first one applies the Augmented Dickey-Fuller (1979) statistic to the residuals from the cointegration equation. Additionally, we also use the tests based on the augmented restricted and unrestricted vector autoregression representation. The results, not shown in the paper, provided consistent evidence supporting the presence of a common unit root between the natural logarithm of both market prices, so that an error correction model for the returns is appropriate.
} 
However, we use an alternative VARMA (vector autoregressive moving average) representation. Consider the $3 x 1$ stochastic vector:

$$
\xi_{t}=\operatorname{vech}\left(\varepsilon_{t} \varepsilon_{t}^{\prime}\right)-\operatorname{vech} \Sigma_{t}
$$

of deviations to the vector of conditional means.

Substituting (14) into (13) and rearranging:

$$
\Gamma_{r}(B) \operatorname{vech}\left(\varepsilon_{t} \varepsilon_{t}^{\prime}\right)=\operatorname{vech} \bar{\Sigma}+\Phi_{p}(B) \xi_{t},
$$

where $\Gamma_{r}(B)=\left[I-\left(\Psi_{p}(B)+\Theta_{q}(B)\right)\right], r=\max \{p, q\}$, and $\Phi_{p}(B)=$ $\left[I-\Psi_{p}(B)\right]$, that is, an $A R M A(r, p)$ representation. Motivated by (16), we posit a pure moving average process for the vector of second order moments of intraday returns:

$$
\operatorname{vech}\left(\varepsilon_{t} \varepsilon_{t}^{\prime}\right)=\operatorname{vech} \bar{\Sigma}+\left(\phi_{1} B+\phi_{2} B^{6}+\phi_{3} B^{12}+\phi_{4} B^{18}\right) \xi_{t} .
$$

which is a version of $(16)$ restricted by $\Psi_{p}(B)=-\Theta_{q}(B)$, together with a particular structure for the $\Psi_{p}(B)$ polynomial, aimed to capture seasonality in variance. If the moving average polynomial has no roots inside the unit circle, this representation captures a dependence among squared innovations potentially spanning up to three market days. The following restrictions are introduced: $a$ ) matrices $\phi_{2}, \phi_{3}$, and $\phi_{4}$ are diagonal, and $b$ ) we assume: $\phi_{12}^{1}=\phi_{21}^{1}=\phi_{22}^{1}=\phi_{23}^{1}=\phi_{32}^{1}=0$, where $\phi_{i j}^{1}$ denotes the $(i, j)$ element in matrix $\phi_{1}$. These restrictions are not relevant concerning the objectives of the paper, and they are made only to avoid the numerical difficulties that would arise when estimating an over-parametrized model. We still permit cross-market interactions between volatilities through $\phi_{31}^{1}$ and $\phi_{13}^{1}$.

Intraday seasonality in volatility is captured by the diagonal elements in matrices $\phi_{j}(j=2,3,4)$, which relate the conditional volatility at a given hour to volatility at the same hour in previous days. The same applies to the conditional covariance. This is more general than previous analysis of the main international stock index futures markets by Park and Switzer (1995), Iihara et al. (1996), Koutmos and Tucker (1996), Racine and Ackert (1999), among others, since in addition to allowing for conditional covariances to change over time, we do not assume the conditional correlation coefficient, i.e., the ratio between the conditional covariance and the product of the conditional standard deviations, to be constant over time. 


\subsection{Estimation results}

Under the assumption of a conditional Gaussian bivariate distribution for the vector of innovations, the $\log$ likelihood for the bivariate $G A R C H$ model is:

$$
L(\theta)=-\frac{1}{2}\left[T \log (2 \pi)+\sum_{t=1}^{T} \log \left|\Sigma_{t}\right|+\varepsilon_{t} \Sigma_{t}^{-1} \varepsilon_{t}^{\prime}\right]
$$

where $\theta$ is the parameter vector to be estimated, and $\varepsilon_{t}=\left(\varepsilon_{s, t} \varepsilon_{f, t}\right)^{\prime}$. The $\log$ likelihood function is highly nonlinear in $\theta$ and a numerical maximization technique is required. We use an exact maximum likelihood algorithm included in the $E 4$ Matlab toolbox ${ }^{6}$, which uses a state space representation of the model. The optimization algorithm used is BFGS (Broyden, Fletcher, Goldfarb and Shanno). Unconditional second order moments are used as initial conditions when generating time series for the conditional variances and covariance. We adopt the following estimation strategy: $a$ ) we first estimate the cointegration equation by ordinary least squares, incorporating the residuals as an exogenous vector in the model, and $b$ ) in consistency with the imposed restrictions, we fix the three elements in vech $\bar{\Sigma}$ to be equal to the estimated unconditional second order moments of market returns in the global sample. Therefore, the numerical algorithm does not iterate in these three parameters. Overall, we have nineteen parameters left to estimate.

Tables 5 and 6 show the results of fitting the bivariate $G A R C H$ model to hourly data on spot and futures market returns. As we should expect, estimated coefficients on the error correction term have opposite signs, although the one in the futures market equation is not significant. The estimated error correction term turned out to be: $s_{t}=0.0505+0.9936 f_{t}$, so that the difference $s_{t-1}-\left(\gamma_{1}+\gamma_{2} f_{t-1}\right)$ can be safely interpreted as the opposite of the empirical basis, i.e., the difference between the futures price and the stock index. This is usually taken as an indicator of the subsequent tendency in the spot market, a large positive basis anticipating an increasing spot market. Our results are consistent with this view: the short-run estimated adjustment predicts that a positive basis, the most frequent case in our sample ${ }^{7}$,

\footnotetext{
${ }^{6}$ This toolbox has been developed in the Departamento de Economía Cuantitativa, Universidad Complutense, Madrid (Spain).

${ }^{7}$ Along the sample period the empirical basis was positive for $74 \%$ of the observed hourly prices.
} 
will tend to be followed by an increase in the spot index, rather than by a downward futures market.

Relative to market interactions, the model suggests one-way causality from the futures to the spot market for both, returns and volatilities. First, there are effects from lagged return innovations in the futures market to returns in the spot market, while a similar effect does not show up in the other direction. Second, the size of lagged innovations in futures market returns influences volatility in both markets, while the size of past innovations in spot market returns does not have any influence on futures market volatility. Finally, our results show a seasonal pattern not only for conditional volatilities of returns in the spot and futures markets, but also for their conditional covariance.

Table 7 reports estimated average volatilities for each trading time interval along the 743 trading sessions. An intraday $U$-shaped curve for both volatilities is shown, suggesting that the opening and closing trading periods have the higher volatility. This empirical finding is consistent with those in Chan et al. (1991) and Daigler (1997).

The average estimated conditional correlation coefficient between innovations in both markets is 0.789 . Such high positive value reflects that innovations in both price processes have most often the same sign and, consequently, futures and spot prices move in the same direction. On the other hand, the estimated correlation is below one, implying that the assumptions required for perfect correlation (no transaction costs and non-stochastic interest rates and dividend yields) are too restrictive. The average conditional variance of returns in the futures market is higher than that of returns in the spot market, this being observed in $75 \%$ of the available data. We will come back to this point in section 5 .

To validate the model, we used three diagnostic tests for the residuals from the estimated $G A R C H$ model: a) a Ljung-Box statistic for the standardized residuals to test the conditional mean specification, b) a Ljung-Box statistic for the squared residuals to test for remaining heteroscedasticity, and c) the $B D S$ statistic proposed by Brock et al. (1986) to test the null hypothesis that the sequence of standardized residuals can be interpreted as realizations from independent and identically distributed random variables. The three suggest that the bivariate error correction $G A R C H$ model successfully captures the dynamics of cross-market interactions between the first and the second order moments of hourly returns. 


\section{Parameter estimates for the theoretical model}

Let us denote by $\hat{\sigma}_{s, t}^{2}, \hat{\sigma}_{f, t}^{2}$ and $\hat{\sigma}_{s f, t}$ the estimated conditional variances and covariance for the spot and futures market return innovations from the GARCH model. To recover estimates for $\sigma_{N, t}^{2}$ and $\rho_{12, t}$ we use the theoretical expressions for the conditional variance of futures market returns and its conditional covariance with spot market returns:

$$
\begin{gathered}
\hat{\sigma}_{f, t}^{2}=\hat{\sigma}_{s, t}^{2}+\hat{\sigma}_{N, t}^{2}+2 \hat{\sigma}_{s, t} \hat{\sigma}_{N, t} \hat{\rho}_{12, t} \\
\hat{\sigma}_{s f, t}=\hat{\sigma}_{s, t}^{2}+\hat{\sigma}_{s, t} \hat{\sigma}_{N, t} \hat{\rho}_{12, t} .
\end{gathered}
$$

$>$ From (20):

$$
\hat{\sigma}_{s, t} \hat{\rho}_{12, t}=\frac{\hat{\sigma}_{s f, t}-\hat{\sigma}_{s, t}^{2}}{\hat{\sigma}_{N, t}} .
$$

Substituting (21) into (19) and rearranging:

$$
\hat{\sigma}_{N, t}^{2}=\hat{\sigma}_{s, t}^{2}+\hat{\sigma}_{f, t}^{2}-2 \hat{\sigma}_{s f, t},
$$

and we recover estimates for the conditional correlation between the common and specific noises from (21) and (22):

$$
\hat{\rho}_{12, t}=\frac{\hat{\sigma}_{s f, t}-\hat{\sigma}_{s, t}^{2}}{\hat{\sigma}_{s, t} \sqrt{\hat{\sigma}_{s, t}^{2}+\hat{\sigma}_{f, t}^{2}-2 \hat{\sigma}_{s f, t}}} .
$$

Finally, the optimal hedge ratio can be estimated from (10) using $\hat{\delta}_{t}=$ $\hat{\sigma}_{N, t} / \hat{\sigma}_{s, t}$ and $\hat{\rho}_{12, t}$. Figures 3 to 5 provide the time evolution for the estimated parameters $\hat{\sigma}_{s, t}^{2}, \hat{\sigma}_{N, t}^{2}$, and $\hat{\rho}_{12, t}$ respectively, for the Ibex 35 spot and futures markets. The conditional standard deviation of the specific noise turns out to be smaller than that of the general market noise in $93 \%$ of the observations. In the remaining $7 \%$ observations $\hat{\sigma}_{N, t}$ is sometimes well higher than $\hat{\sigma}_{s, t}$. Consequently, the ratio $\hat{\delta}_{t}=\frac{\hat{\sigma}_{N, t}}{\hat{\sigma}_{s, t}}$ oscillates between 0.10 and 3.71 , but with an average value of 0.67 . On the other hand, the correlation $\widehat{\rho}_{12, t}$ between the specific and common noises is most often negative, so that either market could turn out to be more volatile than the other. In fact, it is easy to show that, under negative $\rho_{12, t}$, the futures market is more volatile than the spot market when $\left|\rho_{12, t}\right|<\frac{1}{2} \delta_{t}$. Mean values over the whole sample are ${ }^{8}$

\footnotetext{
${ }^{8}$ Expression (23) applied to average volatilities and covariance produces $\widehat{\rho}_{12, t}=-.22$, very close to the sample average of -.26 .
} 
$\widehat{\rho}_{12, t}=-0.26$ and $\widehat{\delta}_{t}=0.67$, so the above inequality holds and the futures market is estimated to be on average more volatile than the spot market, as was already shown in Table 7 . In fact, $\hat{\sigma}_{f, t}^{2}>\hat{\sigma}_{s, t}^{2}$ is observed in $75 \%$ of the available data.

For our average estimated standard deviation ratio $\widehat{\delta}_{t}=0.67$, a perfect, positive correlation $\rho_{12, t}=1$ between the common and specific noises would lead to an optimal hedge ratio of 0.60 , and the return of the hedged position would have zero variance. The optimal hedge ratio would increase for smaller values of $\rho_{12, t}$, reaching 0.69 when $\rho_{12, t}=.0$, the variance of daily returns of the hedged position then being $31 \%$ of the variance of the unhedged position (the market). An optimal unit hedge ratio would arise for a correlation of $\rho_{12, t}=-0.67$, and the variance of the hedged position would be $45 \%$ of the market variance. This is the minimum reduction in variance that is achieved when $\widehat{\delta}_{t}=0.67$. From there, even more negative correlations would make the hedge ratio to rapidly increase, while the variance of the hedged position would again converge to zero. From (10), our estimated average correlation of $\rho_{12, t}=-0.26$ would lead to an optimal hedge ratio of $h^{*} / b=0.76$, and a variance reduction factor of 0.38 , provided coefficients were stable at their estimated values on the full sample. In fact, Table 8 shows that there is enough parameter variation so that annual mean values of the main variables change significantly over time.

\section{Simulated hedging operations}

To calibrate the effectiveness of the optimal hedge ratio characterized in previous sections, we simulate a hedging operation using actual market data for each of the twelve futures contracts maturing in 1996. For this exercise, we start from an estimation of model in Section 2 with data up to December 1995, designing the hedging strategy on the basis of out-of-sample forecasts. The hedging position is revised every Friday, when the model is estimated again, and a forecast of the optimal hedge ratio to be applied over the next week is obtained ${ }^{9}$. In three cases, a market holiday fell on a Friday and the hedging position was revised the previous market day. Every Friday, futures contracts were either bought or sold, as needed, to match the forecasted

\footnotetext{
${ }^{9}$ Experiments using the ex-ante hedge ratio calculated with the subsample used in estimation, or the average of that ratio and the one predicted for the last day of the week, yielded similar results to those reported in Table 8.
} 
hedge ratio. To obtain net returns, we computed the cost of the weekly hedging operation taking into account $a$ ) the bid-ask spread, by paying the ask price when buying a futures contract, and receiving the bid price when selling the contract, and $b$ ) round-trip costs (50 pesetas/contract $)^{10}$. Futures contracts mature the third Friday of each month. At that point, we perform a new simulation for the next contract starting with an initial portfolio which consists of a spot Ibex 35 basket, hedged with our estimated GARCH ratio.

Weekly hedging effectiveness is measured as the percent reduction in volatility of hourly returns from the hedged position during that week, relative to those obtained by the unhedged position,

$$
100 \times \frac{\text { volatility }(\text { hedged position })-\text { volatility }(\text { unhedged position })}{\text { volatility }(\text { unhedged position })} .
$$

Following the discussion in section 2, we start by comparing the standard deviation of the returns offered by the hedged position, with that for market returns (the unhedged position). As a benchmark, we also use the portfolio hedged with a unit ratio. The first column in Table 9 shows the average hedge ratio over the life of each contract. The average ratio over the 12 contracts maturing during 1996 is 0.92 , in line with the 0.88 ratio obtained in Table 8 from the parameter estimates for 1996. Thus, the number of futures contracts involved in the hedging strategy under the estimated ratio is $8 \%$ lower than under the unit hedge ratio and, as a consequence, transaction costs and capital requirements are smaller than when a unit ratio is systematically applied. In fact, the reduction in the number of futures contracts should generally be expected to be more important. Table 8 shows that estimating with 1994 data leads to an average hedge ratio of just $54.1 \%$, and a $52 \%$ expected reduction on variance, while estimates for 1995 produce a $63.4 \%$ hedge ratio and a $43 \%$ expected reduction in return variance. Hence, the number of futures contracts needed for hedging would have been much lower than that used in hedging with a unit ratio in either of those two years.

The next two columns present out-of-sample effectiveness for the predicted hedge ratio, as well as for the constant unit ratio over the last month of life of each contract. Hedging effectiveness under both strategies turns

\footnotetext{
${ }^{10}$ For the period under analysis, Circular 17/93 from MEFF established 70 pesetas per contract as the maximum transaction cost. However, traders negotiating on their own account have variable discounts proportional to the negotiated number of contracts. Consulted market-makers consider 50 pesetas/contract to be a representative average roundtrip cost.
} 
out to be quite similar: over the 12 contracts maturing during 1996, median reduction in volatility was of $58.3 \%$ for the $G A R C H$ ratio, and $57.6 \%$ for the unit ratio, respectively. Both hedged positions reduced the variance of returns, relative to those offered by the market, in 10 of the 12 contracts. In fact, over the 53 weeks considered in our out-of-sample simulation, the $G A R C H$ ratio produced a lower return variance than the unhedged position in 40 weeks, and a lower return variance than the unit ratio in 33 weeks. Median weekly reduction in return variance relative to the market was again similar, $60.6 \%$ for the $G A R C H$ ratio and $59.8 \%$ for the unit ratio. As expected, these numbers improve upon the variance reduction factor of 0.19 which, as shown in Table 8, should be obtained for an ex-post, constant parameter simulation.

For a full comparison between the two hedging strategies, we applied a version of Kolmogorov-Smirnov statistic to test for equality of the empirical distributions of returns from the two hedged portfolios over each of the 12 contracts. We first produced a single list of all hourly returns observed under either hedging strategy. The test was then applied by comparing the values of the empirical distribution function under each strategy, for each observation in the full sample of returns. Working with all individual observations should lead to increased power in the Kolmogorov-Smirnov test. Table 9 shows that the null hypothesis of equal return distributions cannot be rejected at any sensible significance level, except for the March contract. In that month, $G A R C H$ hedging led to $17 \%$ reduction in volatility relative to the market, for a $77 \%$ reduction of the unit hedge ratio.

Even though our theoretical model is developed in terms of volatility of returns, it may also be of interest to consider price volatility. To that extent, we use Garman-Klass (1980) statistic, applied to the six hourly data points, to compute daily volatility of the market price of the hedged and unhedged positions. The overwhelming evidence of non-stationarity of prices suggests using this measure of volatility as opposed to the standard deviation, which could produce misleading conclusions. The $G A R C H$ ratio led to lower volatility than the unhedged position in 50 out of the 53 weeks, and lower volatility than the unit hedge ratio in 31 weeks ${ }^{11}$. Median reduction in price volatility relative to the market was of $90.6 \%$ for the $G A R C H$ ratio, for a

\footnotetext{
${ }^{11}$ The $G A R C H$ ratio produced lower volatility than the unit ratio in 121 days, for 130 days in which the volatility under the unit ratio was lower. That the daily performance of the unit ratio is more often better is due to the fact that the weeks when the unit ratio does better, it produces lower volatility in a majority of days.
} 
reduction of $92.7 \%$ of the unit ratio.

According to either measure, hedging strategies did not perform well during August and September, and the $G A R C H$ ratio did not work very well over March either. March brought rather extreme volatility, being the monthly median Garman-Klass volatility 2.56 times annual median volatility. That kind of unusual volatility seems to quickly deteriorate the performance of hedge ratios below 1. Median daily price volatility in August was 15\% higher than over the whole year. A similar argument could not explain the poor performance of both hedging strategies over September, when volatility remained below annual volatility. Besides, hedging turned out to be quite successful in July, in spite of volatility being $39 \%$ over the annual median. Reflecting the poor hedging performance, correlation coefficients between daily market returns and those obtained from each of the two hedged portfolios were high, between 0.55 and 0.60, during August and September. Return correlations between the market and the $G A R C H$ hedged portfolio was also high in March, of 0.62. This suggests that there are conditions other than the level of volatility affecting hedging performance. Characterizing them remains an interesting issue for further research.

It is also useful to consider the economic benefits from hedging, as obtained from some specification for the hedger's utility function. Let us assume a mean-variance expected utility function as in Kroner and Sultan (1993), $E_{t} U(x)=E_{t}(x)-\gamma \operatorname{Var}_{t}(x)$, where $\gamma$ has the interpretation of the degree of risk aversion and risk is measured by the conditional variance of returns. Weekly variance of returns from the unhedged position was .11368 over 1996 . Average variance for the hedged position ${ }^{12}, \sigma_{t}^{2}=\sigma_{s, t}^{2}-2 \sigma_{s f, t} \frac{h_{t}^{*}}{b_{t}}+\sigma_{f, t}^{2}\left(\frac{h_{t}^{*}}{b_{t}}\right)^{2}$ was .07503 when the $G A R C H$ ratio was used, being .07578 when a unit ratio was sistematically used. Hence, under a null expected return for the hedged portfolio, and with a risk aversion value $\gamma=4$, we obtain an average weekly utility of $U(x)=-4(.11368)=-.45470$ for the unhedged position, $-y-4(.07503)=-y-.30012$ for the position hedged with the $G A R C H$ ratio, where $y$ denotes transaction costs as a rate of return, and $-4(.07578)=-.30312$ under a unit hedge ratio. Hence, the investor's weekly utility increases, on average, by $(.00300-y)$ if he uses the conditional hedge

\footnotetext{
${ }^{12}$ Using the definition for $\delta_{t}, \delta_{t}=\frac{\sigma_{N, t}}{\sigma_{s, t}}$, and the relationships, $\sigma_{f, t}^{2}=\sigma_{s, t}^{2}+\sigma_{N, t}^{2}+$ $2 \rho_{12, t} \sigma_{N, t} \sigma_{s, t}, \sigma_{s f, t}=\sigma_{s, t}^{2}+\rho_{12, t} \sigma_{N, t} \sigma_{s, t}$, it is not hard to show that expression (8) for the variance of the hedged portfolio can be written as, $\left.b_{t}^{2} \quad \sigma_{s, t}^{2}-2 \sigma_{s f, t} \frac{h_{t}^{*}}{b_{t}}+\sigma_{f, t}^{2}\left(\frac{h_{t}^{*}}{b_{t}}\right)^{2}\right]$.
} 
rather than the unit ratio, which is what he will do so long as $y<.00300$. But we have already mentioned that transaction costs for the Spanish market are at most 70 pesetas per contract, which for an average cost of 407038 pesetas of replicating the Ibex35 basket, amounts to a negative return of $.017 \%$. Therefore, even though the reduction in weekly variance is not too large, the conditional hedge increases average utility for an investor with a mean-variance utility and a risk aversion coefficient $\gamma=4$, even after accounting for transaction costs. Relative to not hedging, the gain of either hedged strategy is obvious.

To approximate a real hedging situation, we can also consider an strategy in which the portfolio is rebalanced each week only when the benefits of doing so offset the associated costs, i.e, when the increased expected utility from rebalancing is large enough to offset the transaction costs of updating the hedge. The return volatility from rebalancing would be $\sigma_{t}^{2}=\sigma_{s, t}^{2}-$ $2 \sigma_{s f, t} \frac{h_{t}^{*}}{b_{t}}+\sigma_{f, t}^{2}\left(\frac{h_{t}^{*}}{b_{t}}\right)^{2}$, while that from maintaining the same hedge would be, $\sigma_{t}^{2}=\sigma_{s, t}^{2}-2 \sigma_{s f, t} \frac{h_{t}^{*^{\prime}}}{b_{t}}+\sigma_{f, t}^{2}\left(\frac{h_{t}^{*^{\prime}}}{b_{t}}\right)^{2}$, where $\frac{h_{t}^{*^{\prime}}}{b_{t}}$ denotes the hedge ratio from the last rebalancing. Therefore, a mean-variance expected utility maximizing investor will rebalance at time $t$ if and only if,

$-y-\gamma\left(\sigma_{s, t}^{2}-2 \sigma_{s f, t} \frac{h_{t}^{*}}{b_{t}}+\sigma_{f, t}^{2}\left(\frac{h_{t}^{*}}{b_{t}}\right)^{2}\right)>-\gamma\left(\sigma_{s, t}^{2}-2 \sigma_{s f, t} \frac{h_{t}^{*^{\prime}}}{b_{t}}+\sigma_{f, t}^{2}\left(\frac{h_{t}^{*^{\prime}}}{b_{t}}\right)^{2}\right)$

An investor following this optional weekly rebalancing strategy over 1996 would have obtained a time aggregate utility level of -15.254 , versus utility levels of -15.606 and -15.763 , had he used the $G A R C H$ ratio or the unit hedge ratio every week, respectively. Years with more volatile ratios, as 1994 and 1995, should be expected to show even more clearly the benefits from optimal rebalancing. The utility level derived from the unhedged portfolio would have been of -23.645 .

\section{Summary and concluding remarks}

We have derived a two period hedging model allowing for departures from the cost-of-carry valuation of a futures contract on a stock index. Assuming a geometric Brownian motion for the dynamics of the spot index, we have modeled mispricing by introducing a specific noise in the dynamics of the 
theoretical futures price, possibly correlated with the noise common to both markets. The optimal hedge ratio is shown to depend on two factors: the relative size of the specific and common noises, and their correlation. A detailed analysis of this theoretical model shows that it can capture many interesting features of practical hedging situations, specially when the stochastic behavior of returns in the spot and futures markets widely differs.

We have provided empirical evidence on the model using data from the Spanish stock index futures market over the sample period from December 1993 to December 1996. A bivariate error correction model with GARCH innovations has been used to estimate the parameters of the theoretical model, from which we have computed estimates for the optimal hedge ratio during this sample period. The model allows for transmission of returns and volatilities between both markets, showing that the futures market has a stronger influence on the spot market aspects than the other way around. Furthermore, we have provided significant evidence on intraday seasonality in volatility in both markets. This model should be a useful tool to discuss different characteristics of the dynamic relationship between spot and futures markets, beyond the implications for hedging exploited in this paper.

Empirical results support that spot and futures markets do not have a common ARCH feature. Our findings suggest that there is a specific noise in the Spanish futures market with a small, negative correlation with the noise common to the spot and futures markets. A negative correlation in the theoretical model does not preclude futures market returns to be more volatile than spot market returns and, in fact, we observe that to be the case in $75 \%$ of the available data.

Ex-ante simulations with actual data reveal that hedge ratios that take into account the estimated, time-varying, correlation between the common and specific disturbances, lead to using a lower number of futures contracts than under a systematic unit ratio, without losing hedging effectiveness. Using less futures contracts for hedging implies lower transaction costs and smaller capital requirements. Besides, the reduction in the number of contracts can be substantial over some periods. Considering an investor with a mean-variance expected utility function, we have also shown that the economic benefits from an optimal conditional hedging are substantial. 


\section{References}

[1] Bhatt, S. and N. Caciki (1990), Premiums on Stock Index Futures: Some Evidence, Journal of Futures Markets 10, 367-375.

[2] Bühler, W. and A. Kempf (1995), DAX index futures: mispricing and arbitrage in German markets, Journal of Futures Markets 7, 833-859.

[3] Brenner, R. and K.F. Kroner (1995), Arbitrage, cointegration and testing for simple efficiency in financial markets, Journal of Financial and Quantitative Analysis 30, 23-42.

[4] Brock, B.W., Dechert, W.D. and J. Scheinkman (1986), A test for independence based in the correlation dimension, Working Paper, University of Wisconsin.

[5] Chan K., Chan, K.C. and G.A. Karolyi (1991), Intraday volatility in the stock index and stock index futures markets, Review of Financial Studies 4, 657-684.

[6] Daigler R.T. (1997), Intraday futures volatility and theories of market behavior, Journal of Futures Markets 17, 45-74.

[7] Dickey, D.A. and W. Fuller (1979), Distribution of the estimators for autoregressive time series with unit root, Journal of the American Statistical Association, 74: 427-431.

[8] Engle, R.F. and C.W. Granger (1987), Cointegration and error correction: Representation, estimation and testing, Econometrica 55, 251-276.

[9] Engle, R.F. and S. Kozicki (1993), Testing for Common Features, Journal of Business and Economic Statistics 11, 369-380.

[10] Fernández, P. and J. Yzaguirre (1996), Ibex 35. Análisis e investigaciones. Ediciones Internacionales Universitarias.

[11] Garman, M. and M. Klass (1980), "On the estimation of security price volatilities from historical data", Journal of Business, 53, 67-78.

[12] Grassberger, P. and I. Procaccia (1983), Measuring the strangeness of strange attractors, Physica 9D: 189-208. 
[13] Iihara Y., Kato, K. and T. Tokunaga (1996), Intraday returns dynamics between cash and the futures markets in Japan, Journal of Futures Markets 16, 147-162.

[14] Koutmos G. and M. Tucker (1996), Temporal relationships and dynamics interactions between spot and futures stock markets, Journal of Futures Markets 16, 55-69.

[15] Kroner, K.F. and J. Sultan (1993), Time-varying distributions and dynamic hedging with foreign currency futures, Journal of Financial and Quantitative Analysis, 28, 535-551.

[16] Lafuente, J.A. (1999), Pautas intradía de volatilidad en el Ibex 35 y el futuro sobre el Ibex 35, mimeo, Universidad Complutense de Madrid.

[17] Lien, D. and Y.K. Tse (1999), Fractional cointegration and futures hedging, Journal of Futures Markets 19, 457-474.

[18] Lim, K. (1992), Arbitrage and price behavior of the Nikkei stock index futures, Journal of Futures Markets 12, 151-161.

[19] Mackinlay, A.C. and C. Ramaswamy (1988), Index futures arbitrage and the behavior of stock index futures prices, Review of Financial Studies $1,137-158$.

[20] Miller, M.H., Muthuswamy, J. and R.E. Whaley (1994), Mean reversion of Standard \& Poor's 500 index basis changes: Arbitrage-induced or statistical illusion?, Journal of Finance 49, 479-513.

[21] Park, T.H. and L.N. Switzer (1995), Bivariate Garch estimation of the optimal hedge ratios for stock index futures: A note, Journal of Futures Markets 15, 61-67.

[22] Pizzi, M.A., Economopoulos, A.J. and H.M. O’Neill (1998), An examination of the relationship between stock index cash and futures markets: A cointegration approach, Journal of Futures Markets 18, 297-305.

[23] Racine, M.D. and L.F. Ackert (1999), Time-varying volatility in Canadian and U.S. stock index and stock index futures markets: A multivariate analysis, Journal of Economics and Business, 51 (2). 
[24] Stoll, H.R. and R.E. Whaley (1990), The dynamics of stock index and stock index futures returns, Journal of Financial and Quantitative Analysis 25, 441-468.

[25] Wahab, M. and M. Lasghari (1993), Price dynamics and error correction in stock index and stock index futures markets: A cointegration approach, Journal of Futures Markets 13, 711-742.

[26] Yadav, P.K. and P.F. Pope (1990), Stock index futures arbitrage: International evidence, Journal of Futures Markets 10, 573-603.

[27] Yadav, P.K. and P.F. Pope (1994), Stock index futures mispricing: Profit opportunities or risk premia?, Journal of Banking and Finance 18, 921953.

[28] Yang S.R. and W. Brorsen (1993), Nonlinear dynamics of daily futures prices: conditional heteroscedasticity or chaos?, Journal of Futures Markets 2, 175-191. 


\section{Appendix 1. First order condition for the hedging model}

Substituting the theoretical dynamics of spot and futures market returns into the objective function, the problem can be written:

$$
\begin{aligned}
& \operatorname{Min} \operatorname{Var}_{t}\left[b_{t}\left(\mu_{s, t}+\sigma_{s, t} \frac{d z_{1, t}}{d t}\right)-h_{t}\left(\mu_{f, t}+\sigma_{s, t} \frac{d z_{1, t}}{d t}+\sigma_{N, t} \frac{d z_{2, t}}{d t}\right)\right] \\
& \left\{h_{t}\right\}
\end{aligned}
$$

Using properties of the variance, and taking into account that $\operatorname{Var}_{t}\left(\frac{d z_{1, t}}{d t}\right)=$ $\operatorname{Var}_{t}\left(\frac{d z_{2, t}}{d t}\right)=1$ and $\operatorname{Cov}_{t}\left(\frac{d z_{1, t}}{d t}, \frac{d z_{2, t}}{d t}\right)=\rho_{12, t}$, we get the expression for the objective function:

$$
b_{t}^{2} \sigma_{s, t}^{2}+h_{t}^{2}\left(\sigma_{s, t}^{2}+\sigma_{N, t}^{2}+2 \rho_{12, t} \sigma_{s, t} \sigma_{N, t}\right)-2 b_{t} h_{t}\left(\sigma_{s, t}^{2}+\rho_{12, t} \sigma_{s, t} \sigma_{N, t}\right)
$$

Setting the derivative with respect to $h_{t}$ equal to zero:

$2\left[h_{t}\left(\sigma_{s, t}^{2}+\sigma_{N, t}^{2}+2 \rho_{12, t} \sigma_{s, t} \sigma_{N, t}\right)-b_{t}\left(\sigma_{s, t}^{2}+\rho_{12, t} \sigma_{s, t} \sigma_{N, t}\right)\right]=0$.

$>$ From (A.3), simplifying and rearranging we obtain equation (10). The second order condition ensures that this hedge ratio is in fact optimum, since:

$$
\frac{\partial^{2} \operatorname{Var}_{t}\left(h_{t}\right)}{\partial h_{t}^{2}}=2\left(\sigma_{s, t}^{2}+\sigma_{N, t}^{2}+2 \rho_{12, t} \sigma_{s, t} \sigma_{N, t}\right)=2 \operatorname{Var}_{t}\left(\frac{d F_{t, T}}{F_{t, T} d t}\right)>0
$$




\section{Appendix 2. Statistical Tables.}

Table 1. Summary statistics. Market returns

\begin{tabular}{lcc}
\hline \hline & Spot Market & Futures market \\
\hline Mean* $10^{3}$ & -0.0281 & 0.0002 \\
Standard deviation & 0.0036 & 0.0030 \\
Skewness & -0.7131 & -0.0582 \\
Kurtosis & 10.7904 & 3.4209 \\
$\rho\left(r_{t}, r_{t-k}\right)^{(a)}$ & & \\
$k=1$ & $0.0758^{*}$ & 0.0241 \\
$k=2$ & 0.0073 & 0.0029 \\
$k=3$ & $0.0542^{*}$ & 0.0139 \\
$k=4$ & 0.0232 & $0.0460^{*}$ \\
$k=5$ & -0.0099 & 0.0181 \\
$k=6$ & -0.0175 & 0.0028 \\
$k=7$ & -0.0231 & $-0.0451^{*}$ \\
$k=8$ & -0.0216 & -0.0121 \\
$k=9$ & -0.0051 & 0.0001 \\
$k=10$ & 0.0144 & $0.0408^{*}$ \\
$k=11$ & 0.0043 & 0.0110 \\
$k=12$ & 0.0250 & $0.0406^{*}$ \\
$k=18$ & 0.0100 & $0.0296^{*}$ \\
$k=24$ & $0.1390^{*}$ & -0.0040 \\
\hline Ljung-Box satistics ${ }^{(b)}$ & $73.41(0.00)$ & $54.39(0.00)$ \\
\hline
\end{tabular}

Notes: ${ }^{(a)}$ Autocorrelation function. The standard error for the autocorrelation coefficients can be approximated by $\frac{1}{\sqrt{4,458}} \simeq 0.015$. An asterisk denotes a coefficient significant at the $5 \%$ level. ${ }^{(b)}$ Ljung-Box test uses 24 autocorrelation coefficients. Its $p$-value is shown in parentheses. 
Table 2. Autocorrelations functions. Squared returns

\begin{tabular}{lcc}
\hline \hline & Spot Market & Futures market \\
\hline$\rho\left(r_{t}^{2}, r_{t-k}^{2}\right)$ & & \\
$k=1$ & $0.0874^{*}$ & $0.1435^{*}$ \\
$k=2$ & -0.0028 & $0.0760^{*}$ \\
$k=3$ & -0.0056 & 0.0261 \\
$k=4$ & 0.0255 & $0.0732^{*}$ \\
$k=5$ & $0.1015^{*}$ & $0.1001^{*}$ \\
$k=6$ & $0.2506^{*}$ & $0.1982^{*}$ \\
$k=7$ & $0.0299^{*}$ & $0.0630^{*}$ \\
$k=8$ & -0.0028 & $0.0397^{*}$ \\
$k=9$ & -0.0135 & $0.0389^{*}$ \\
$k=10$ & 0.0028 & $0.0315^{*}$ \\
$k=11$ & 0.0241 & $0.0820^{*}$ \\
$k=12$ & $0.1341^{*}$ & $0.1464^{*}$ \\
$k=18$ & $0.1697^{*}$ & $0.1183^{*}$ \\
$k=24$ & $0.1591^{*}$ & $0.1325^{*}$ \\
\hline Ljung-Box statistics ${ }^{(b)}$ & $724.08(0.00)$ & $800.83(0.00)$ \\
\hline
\end{tabular}

Notes: ${ }^{(a)}$ Autocorrelation function. The standard error for the autocorrelation coefficients can be approximated by $\frac{1}{\sqrt{4,458}} \simeq 0.015$. An asterisk denotes a coefficient significant at the $5 \%$ level. ${ }^{(b)}$ Ljung-Box test uses 24 autocorrelation coefficients. Its $p$-value is shown in parentheses. 
Table 3. Cross correlation functions

\begin{tabular}{|c|c|c|}
\hline & Returns & Squared returns \\
\hline & $\rho\left(r_{s, t}, r_{f, t-k}\right)^{(*)}$ & $\rho\left(r_{s, t}^{2}, r_{f, t-k}^{2}\right)$ \\
\hline$k=-24$ & 0.0062 & $0.0617^{*}$ \\
\hline$k=-18$ & $0.0321^{*}$ & $0.0618^{*}$ \\
\hline$k=-12$ & $0.0415^{*}$ & $0.0881^{*}$ \\
\hline$k=-11$ & 0.0003 & $0.1191^{*}$ \\
\hline$k=-10$ & $0.0353^{*}$ & $0.0740^{*}$ \\
\hline$k=-9$ & -0.0051 & 0.0105 \\
\hline$k=-8$ & -0.0066 & 0.0307 \\
\hline$k=-7$ & -0.0281 & 0.0215 \\
\hline$k=-6$ & -0.0081 & $0.1194^{*}$ \\
\hline$k=-5$ & -0.0179 & $0.2490^{*}$ \\
\hline$k=-4$ & 0.0144 & $0.0527^{*}$ \\
\hline$k=-3$ & 0.0281 & 0.0201 \\
\hline$k=-2$ & 0.0123 & 0.0195 \\
\hline$k=-1$ & $0.0309^{*}$ & $0.1037^{*}$ \\
\hline$k=0$ & $0.6708^{*}$ & $0.3457^{*}$ \\
\hline$k=1$ & $0.1275^{*}$ & $0.1724^{*}$ \\
\hline$k=2$ & 0.0198 & $0.0333^{*}$ \\
\hline$k=3$ & $0.0358^{*}$ & $0.0295^{*}$ \\
\hline$k=4$ & 0.0255 & $0.0388^{*}$ \\
\hline$k=5$ & $0.0314^{*}$ & $0.0421^{*}$ \\
\hline$k=6$ & 0.0102 & $0.0958^{*}$ \\
\hline$k=7$ & $-0.0301^{*}$ & $0.1187^{*}$ \\
\hline$k=8$ & $-0.0392^{*}$ & $0.0307^{*}$ \\
\hline$k=9$ & 0.0007 & 0.0245 \\
\hline$k=10$ & 0.0117 & 0.0012 \\
\hline$k=11$ & 0.0149 & 0.0048 \\
\hline$k=12$ & 0.0268 & $0.0569^{*}$ \\
\hline$k=18$ & 0.0232 & $0.0754^{*}$ \\
\hline$k=24$ & 0.0094 & $0.0632^{*}$ \\
\hline
\end{tabular}

Notes: ${ }^{(*)} r_{s, t}$ and $r_{f, t-k}$ denote spot and futures market returns in periods $t$ and $t-k$, respectively. The standard error for each cross-correlation coefficient can be approximated by $\frac{1}{\sqrt{4,458}} \simeq 0.015$. An asterisk denotes a coefficient significant at the $5 \%$ level. 
Table 4. Common $A R C H$ features tests

\begin{tabular}{lllllllllll}
\hline \hline$k$ & 1 & 2 & 3 & 4 & 5 & 6 & 7 & 8 & 9 & 10 \\
$d f$ & 2 & 5 & 8 & 11 & 14 & 17 & 20 & 23 & 26 & 29 \\
$\min T R^{2}$ & 15.4 & 17.3 & 20.6 & 20.7 & 41.2 & 121.7 & 147.4 & 154.8 & 155.0 & 155.8 \\
\hline Critical values & & & & & & & & & & \\
$\alpha=.05$ & 6.0 & 11.1 & 15.5 & 19.7 & 23.7 & 27.6 & 31.4 & 35.2 & 38.9 & 42.6 \\
$\alpha=.01$ & 9.2 & 15.1 & 20.1 & 24.7 & 29.1 & 33.4 & 37.6 & 41.6 & 45.6 & 49.6 \\
\hline
\end{tabular}

Notes: $\min T R^{2}$ shows $T$ times the minimum $R^{2}$-squared coefficient in a set of regressions of $\left(r_{s, t}-\delta r_{f, t}\right)^{2}$ on $k$ lags of $r_{s, t}^{2}, r_{f, t}^{2}$, and $r_{s, t} r_{f, t}$. $d f$ denotes the degrees of freedom for each value of $k$. The last two rows show critical values at the $\alpha$-significance levels.

Table 5. Maximum likelihood estimation. Equation for mean returns

\begin{tabular}{cc|cc}
\hline \hline \multicolumn{4}{c}{ Dependent variable } \\
\hline \multicolumn{2}{c}{ Spot market return ${ }^{(a)}$} & \multicolumn{2}{c}{ Futures market return } \\
\hline coefficient & coefficient \\
$\alpha_{11}$ & $0.061(0.017)^{*}$ & $\alpha_{21}$ & $-0.006(0.014)$ \\
$\alpha_{12}$ & $-0.106(0.021)^{*}$ & $\alpha_{22}$ & $-0.032(0.018)$ \\
$\beta_{s}$ & $-0.078(0.014)^{*}$ & $\beta_{f}$ & $0.012(0.012)$ \\
\hline
\end{tabular}

Note: ${ }^{(a)}$ Estimated standard errors in parentheses. An asterisk denotes a coefficient significant at the $5 \%$ level.

Table 6. Maximum likelihood estimation. Variance equation

\begin{tabular}{|c|c|c|c|c|c|}
\hline \multicolumn{6}{|c|}{ Dependent variable $^{(a)}$} \\
\hline & $\varepsilon_{s, t}$ & & $\varepsilon_{f, t}$ & & $\varepsilon_{s, t} \varepsilon_{f, t}$ \\
\hline $\begin{array}{l}\text { coefficient } \\
\alpha^{1}(b)\end{array}$ & (ח $(\cap \cap 04)$ & coefficient & $\cap 0 \cap 4(\cap 002)$ & coefficient & $0078(\cap 008) *$ \\
\hline $\begin{array}{l}\phi_{11} \\
\phi_{12}^{1}\end{array}$ & $0.065(0.011)^{*}$ & $\begin{array}{l}\phi_{31} \\
\phi_{32}^{1}\end{array}$ & $0.036(0.008)^{*}$ & $\begin{array}{l}\phi_{22} \\
\phi_{20}^{3}\end{array}$ & $0.012(0.007)^{*}$ \\
\hline$\phi_{11}^{2}$ & $0.136(0.004)^{*}$ & $\phi_{33}^{2}$ & $0.036(0.011)^{*}$ & $\phi_{22}^{4}$ & $0.007(0.005)$ \\
\hline$\phi_{11}^{3}$ & $0.077(0.007)^{*}$ & $\phi_{33}^{3}$ & $0.051(0.008)^{*}$ & & \\
\hline$\phi_{11}^{4}$ & $0.068(0.004)^{*}$ & $\phi_{33}^{4}$ & $0.035(0.005)^{*}$ & & \\
\hline
\end{tabular}

Note: ${ }^{(a)}$ Estimated standard errors in parentheses. An asterisk denotes a coefficient significant at the $5 \%$ level. ${ }^{(b)} \phi_{i j}^{r}$ denotes the $(i, j)$ element in matrix $\phi_{r}(r=1,2,3,4)$. 
Table 7. Average intraday statistics from the $G A R C H$ model

\begin{tabular}{lcccc}
\hline \hline \multirow{2}{*}{$\begin{array}{l}\text { Trading } \\
\text { hour intervals }\end{array}$} & \begin{tabular}{c} 
Spot \\
\cline { 2 - 5 } Volatility
\end{tabular}$\sigma_{s, t}^{2}$ & $\begin{array}{c}\text { Futures } \\
\text { Volatility } \sigma_{f, t}^{2}\end{array}$ & $\begin{array}{c}\text { Spot-Futures } \\
\text { Covariance } \sigma_{s f, t}\end{array}$ & $\begin{array}{c}\text { Conditional } \\
\text { Correlation } \rho_{s f, t}\end{array}$ \\
\hline 11:00 - 12:00 & 0.092 & 0.164 & 0.083 & 0.672 \\
12:00 - 13:00 & 0.083 & 0.089 & 0.069 & 0.808 \\
13:00 - 14:00 & 0.081 & 0.084 & 0.068 & 0.830 \\
14:00 - 15:00 & 0.084 & 0.086 & 0.070 & 0.823 \\
15:00 - 16:00 & 0.086 & 0.090 & 0.072 & 0.813 \\
16:00 - 17:00 & 0.101 & 0.107 & 0.082 & 0.789 \\
\hline Global & 0.088 & 0.103 & 0.075 & 0.789 \\
\hline
\end{tabular}

Note: ${ }^{(a)}$ Each entry is the average of $G A R C H$ moments estimated using daily data up to the time shown as the upper end of each interval. There are 743 data points in each of these samples. The last row uses all data points.

Table 8. Annual mean estimates for the main variables

\begin{tabular}{|c|c|c|c|c|c|c|c|c|}
\hline & & & & & & & & Variance \\
\hline & $\sigma_{f}^{2}$ & $\overline{\sigma_{s}^{2}}$ & $\sigma_{s f}$ & $\overline{\sigma_{N}^{2}}$ & $\delta$ & $\rho_{12}$ & $\frac{h^{*}}{b}$ & reduction factor \\
\hline 1994 & 0.225 & 0.126 & 0.114 & 0.123 & 0.951 & -0.088 & 0.54 & 0.52 \\
\hline 1995 & 0.118 & 0.076 & 0.067 & 0.060 & 0.807 & -0.085 & 0.63 & 0.43 \\
\hline 1996 & 0.051 & 0.048 & 0.043 & 0.013 & 0.448 & -0.176 & 0.88 & 0.19 \\
\hline Full Sample & 0.103 & 0.088 & 0.071 & 0.049 & 0.669 & -0.265 & 0.76 & 0.38 \\
\hline
\end{tabular}


Table 9. Median Hedging effectiveness ${ }^{(1)}$

\begin{tabular}{|c|c|c|c|c|c|c|}
\hline \multirow[b]{3}{*}{ Maturity } & \multirow{3}{*}{$\begin{array}{c}G A R C H \\
\text { hedge } \\
\text { ratio }\end{array}$} & \multirow{2}{*}{\multicolumn{2}{|c|}{$\begin{array}{c}\text { Reduction in standard } \\
\text { deviation of returns } \\
\text { Hedge ratio }\end{array}$}} & \multirow{3}{*}{$\begin{array}{l}\text { Kolmogorov } \\
\text { Smirnov test }\end{array}$} & \multirow{2}{*}{\multicolumn{2}{|c|}{$\begin{array}{c}\text { Reduction in } \\
\text { Garman Klass volati } \\
\text { Hedge ratio }\end{array}$}} \\
\hline & & & & & & \\
\hline & & $G A R C H$ & Unit & & $G A R C H$ & $\overline{\text { Unit }}$ \\
\hline January 96 & .918 & $63.0 \%$ & $62.7 \%$ & $0.604(0.859)$ & $89.9 \%$ & $92.2 \%$ \\
\hline February 96 & .920 & $55.9 \%$ & $53.4 \%$ & $0.389(0.998)$ & $20.0 \%$ & $7.3 \%$ \\
\hline March 96 & .912 & $17.1 \%$ & $76.9 \%$ & $1.862(0.002)$ & $38.4 \%$ & $94.2 \%$ \\
\hline April 96 & .898 & $61.5 \%$ & $58.6 \%$ & $0.618(0.839)$ & $90.5 \%$ & $90.6 \%$ \\
\hline May 96 & .942 & $58.6 \%$ & $56.6 \%$ & $0.493(0.969)$ & $94.7 \%$ & $94.8 \%$ \\
\hline June 96 & .935 & $67.5 \%$ & $67.5 \%$ & $0.591(0.876)$ & $92.1 \%$ & $93.8 \%$ \\
\hline July 96 & .944 & $73.3 \%$ & $72.5 \%$ & $0.713(0.689)$ & $95.5 \%$ & $97.0 \%$ \\
\hline August 96 & .864 & $-14.6 \%$ & $-22.2 \%$ & $0.342(0.999)$ & $33.5 \%$ & $39.3 \%$ \\
\hline September 96 & .914 & $-40.0 \%$ & $-39.5 \%$ & $0.232(0.999)$ & $14.1 \%$ & $17.6 \%$ \\
\hline October 96 & .920 & $58.0 \%$ & $54.3 \%$ & $0.583(0.885)$ & $90.6 \%$ & $88.3 \%$ \\
\hline November 96 & .932 & $43.6 \%$ & $53.3 \%$ & $0.414(0.995)$ & $90.6 \%$ & $93.2 \%$ \\
\hline December 96 & .936 & $59.3 \%$ & $59.5 \%$ & $0.466(0.982)$ & $96.8 \%$ & $95.2 \%$ \\
\hline MEDIAN & .920 & $58.3 \%$ & $57.6 \%$ & & $90.6 \%$ & $92.7 \%$ \\
\hline
\end{tabular}

(1) Hedging effectiveness is defined as the percent reduction in either weekly standard deviation of returns(left panel) or daily Garman-Klass volatility (right panel), in both cases relative to the market (the unhedged position), over the last month of each contract.

(2) The null hypothesis is that empirical distributions of returns from the two hedged positions are the same. $p$-values are shown in parentheses. 


\section{Figures}

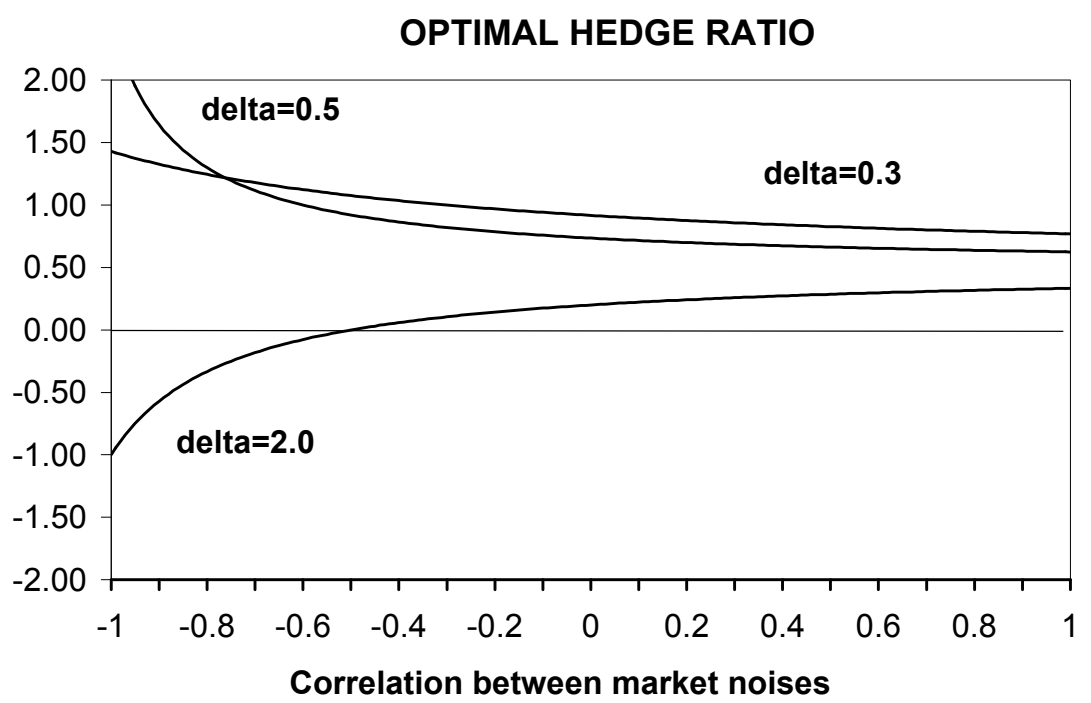

Figure 1.

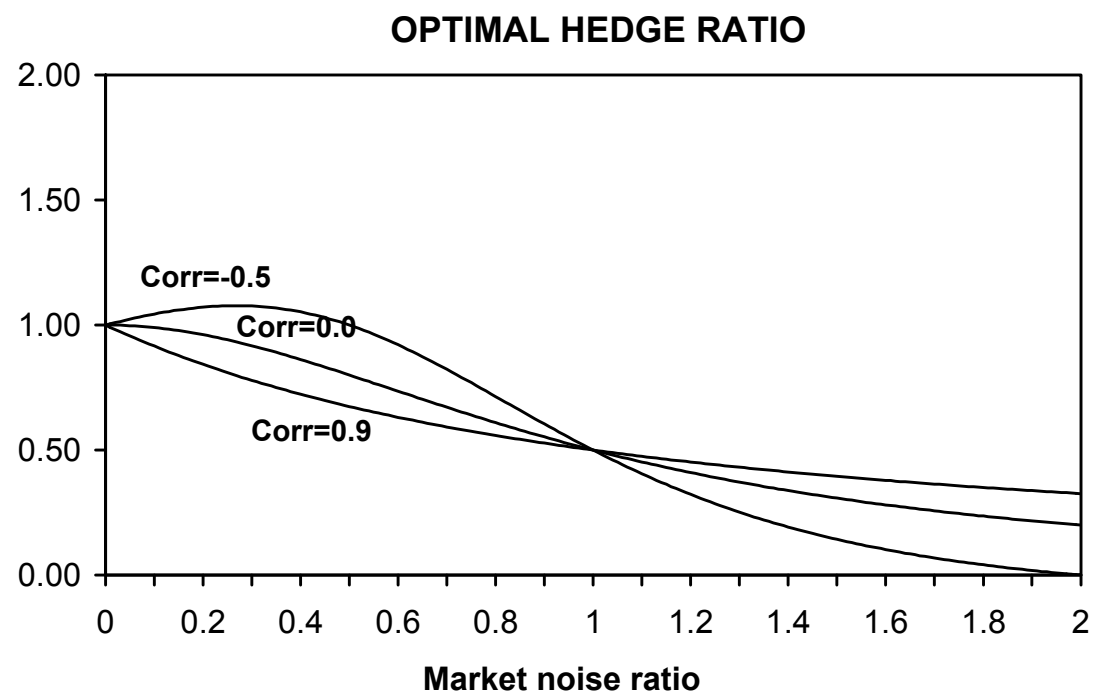

Figure 2. 


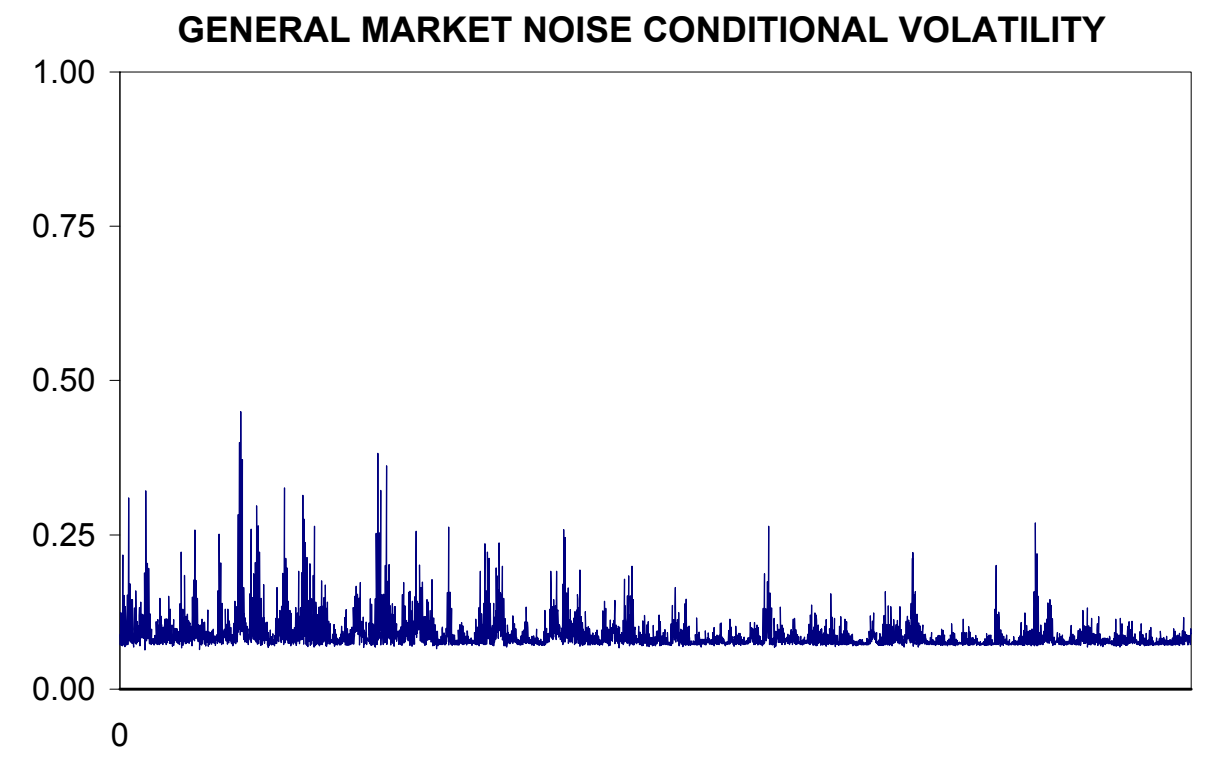

Figure 3.

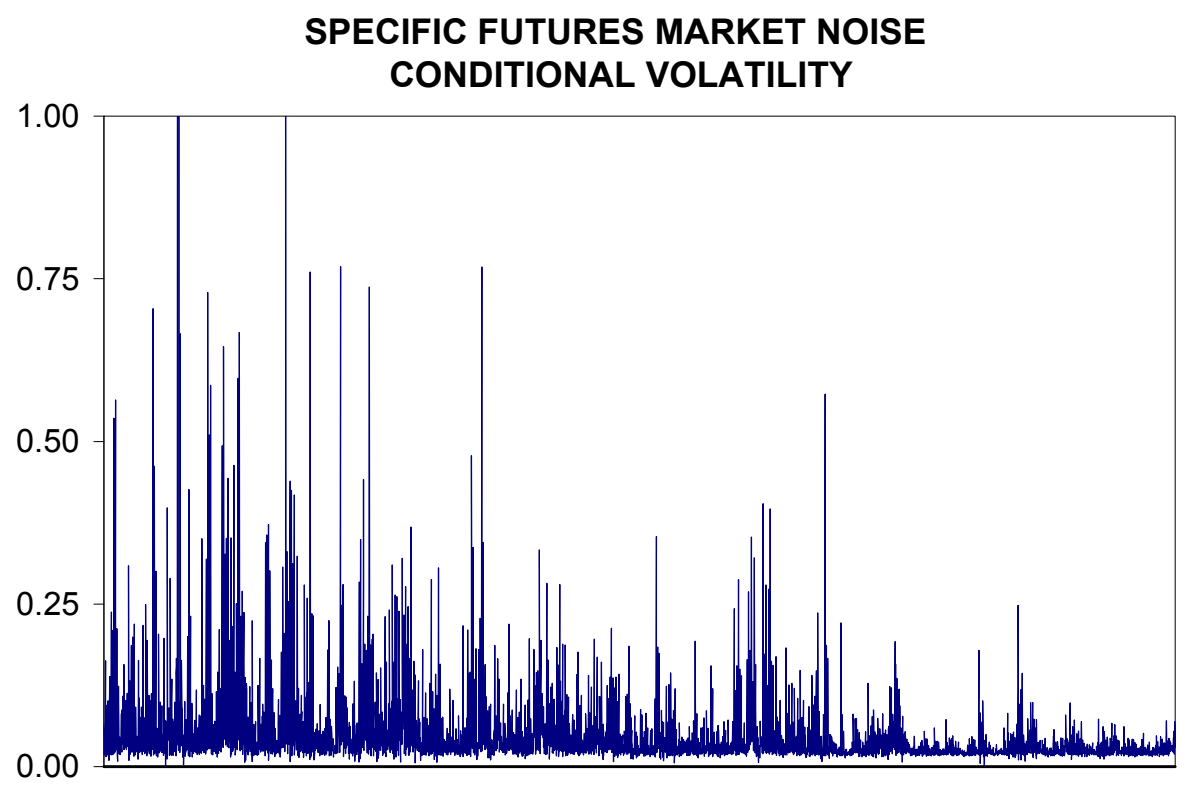

Figure 4. 


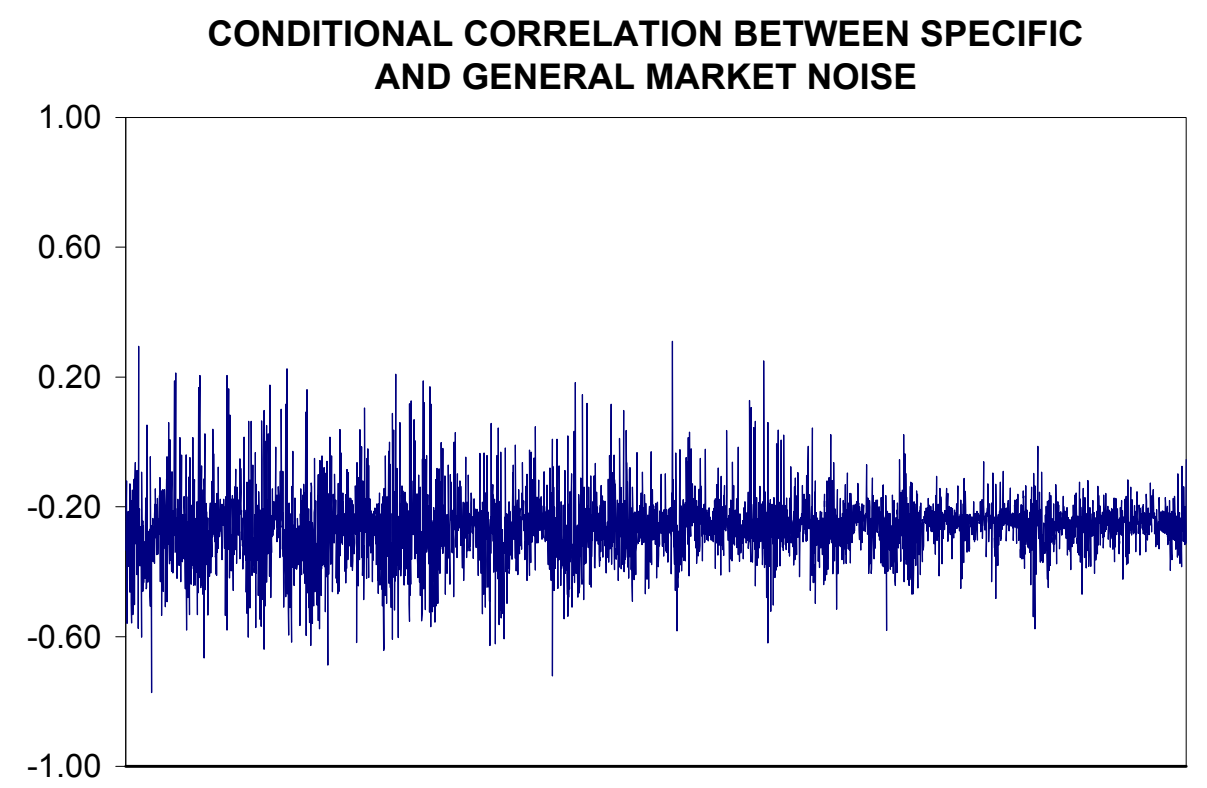

Figure 5. 